\title{
Monitoring of Movement on the Farm Using WiFi Technology
}

Vojtěch Novák, Michal Stočes, Eva Kánská, Jan Pavlík, Jan Jarolímek

Faculty of Economics and Management, Czech University of Life Sciences in Prague, Czech Republic

\begin{abstract}
The paper deals with using commercial WiFi solutions that provide wireless connection to computer networks to monitor the movement of devices within that network. Current technologies, in particular in the IoT area, make it possible to place a battery sensory device on individual objects used on the farm. These sensors, in addition to their primary ability to provide connectivity, can also be used to monitor the movement of the devices they are attached to. Indirectly, it is therefore possible to monitor the movement of objects, people and animals that are associated with this WiFi or Bluetooth device. An example could be the monitoring of the feed wagon's movement on the farm, while obtaining information about the actual amount of cargo. This allows for optimizing logistics operations or track the movement of employees with fitness bracelets. The aim of the paper is to verify the possibilities of currently available commercial wifi systems and their use for monitoring movement on the farm.
\end{abstract}

\section{Keywords}

Wi-Fi, Cloud, protocols, networks, position, Meraki, Aruba, Precision Agriculture, Smart Agriculture.

Novák, V., Stočes, M., Kánská, E., Pavlík, J. and Jarolímek, J. (2019) "Monitoring of Movement on the Farm Using WiFi Technology", AGRIS on-line Papers in Economics and Informatics, Vol. 11, No. 4, pp. 85-92. ISSN 1804-1930. DOI 10.7160/aol.2019.110408.

\section{Introduction}

Farms are increasingly starting to build a communication infrastructure for wireless Internet access (WiFi). This paper acknowledges that fact and tries to find further possible uses for such networks and determine potential negative implications resulting from building these networks. For example, farmers can ensure better monitoring of the environment by using IoT sensors, offering better tools for employee collaboration, or helping to save lives and property. Mainly thanks to localization and monitoring of movement of specific objects, assuming that the objects in question are tied to a specific WiFi or Bluetooth device.

One of the core technologies for disaster management is the indoor positioning system, which can help rescue more people and prevent property loss due to the accurate and rapid localization of people and assets at the beginning of a disaster (Li et al., 2019; Kola-Bezka et al., 2016).

Internet of Things (IoT) issues are increasingly more important and experience dramatic development in many areas. Such development brings many new technological innovations as well as generates new problems. Vast quantities of IoT devices in use or still in development need to be categorized based on their usage, type, internet connection, place of implementation etc. One of the important places of usage is agrarian sector and countryside in general. It belongs to one of the more "traditional" areas of IoT implementation, but there is still a lot of room for further development (Stočes et al., 2016).

Underground mine locomotive monitoring and tracking management system expands mining rail net existing capacity, to increase traffic density of mining locomotive, real-time provide the position information, avoid traffic accidents and greatly enhance the transportation safety and production efficiency (Song and Liu, 2011).

Experimental results show that location system has accuracy about of $96 \%$ within 2.5 metres. However, this is only when three access point are available for establishing the position; in other cases, the accuracy is reduced. It is possible to combine the triangulation method with probability distributions of received signal strength to improve these results as shown by (Sanchez et al., 2006).

(Vasisht et al., 2016) presents Chronos, a system that measures sub-nanosecond time-of-flight on commercial WiFi radios. Chronos uses these 
measurements to enable $\mathrm{WiFi}$ device-to-device positioning at state-of-the-art accuracy, without support of additional WiFi infrastructure or non-WiFi sensors. By doing so, Chronos opens up WiFi-based positioning to new applications where additional infrastructure and sensors may be unavailable or inaccessible, e.g., geo-fencing, home occupancy measurements, finding lost devices, maintaining robotic formations, etc.

Most authors are more concerned with the issue from the perspective of the technological possibilities, and most solutions presented use proprietary systems, for example (Longo et al., 2019; Jermolajeva et al., 2017; Zelazny, 2017). While the aim of this article is to verify the possibilities of currently available commercial systems, or to compare them with each other.

\section{Materials and methods}

The following principles, methods and technologies were used in the research at the Faculty of Economics and Management at Czech University of Life Sciences Prague. We focused on methods of monitoring the movement of logistic elements within the farm using commercial solutions for management of WiFi networks.

\section{Signal attenuation (RSSI method)}

RSSI was considered as a metric in most of the distance measurement algorithms. Even though the ineffectiveness of RSSI is mentioned in the literature, not many attempts were made to implement it in a practical environment and verify it. (Elnahrawy et al., 2004; Parameswaran et al., 2009) have explored the idea of using RSSI in localization algorithms conducted in indoor environments and determined that more complex models and algorithms are required to improve accuracy of RSSI based methods when used indoors.

The advantage of using the signal attenuation is that no specialized hardware is required as the transmitter module measures the signal strength anyway. Imprecision in the distance estimation can occur though, caused by signal attenuation that is introduced by obstacles or reflections. This raises a major problem for indoor environments, where no simple signal propagation model can be applied unlike in a free space environment. For this reason, in indoor setups the signal attenuation is usually only used as an attribute for the subsequently described fingerprinting technique where the signal strength is measured in advance at different locations of the site (Fuchs et al., 2011).
Algorithms based on matching and signal-to distance functions are unable to capture the myriad of effects on signal propagation in an indoor environment. While many of the algorithms can explore the space of this uncertainty in useful ways, e.g., by returning likely areas and rooms, they cannot provide precise position. Still, the localization accuracy is significant and useful, as showed when mapping the objects into rooms (Elnahrawy et al., 2004).

\section{Fingerprinting}

A different technique for localization called fingerprinting uses in-advance mapped properties of the environment for position estimation. For example, the received signal strength of a WLAN signal is measured at as many different locations as possible within the target area. This information is saved including its spatial mapping. A sensor that wants to locate itself measures its current signal strength pattern and compares it to the pre-generated signal map. The closest match in the map is then assumed as the actual position.

The disadvantage of this method is the high initial effort that is caused by the mapping of the attributes of the environment. Consequently, this technique is not suited for unknown sites as there is no information available on the property used for the pattern matching. For this reason, fingerprinting does not comply to the requirements for the intended use case in mission-critical scenarios, because it requires a site-specific training and doesn't provide consistent results when structural changes happen in the environment. Tracking systems that use this technique can therefore be excluded from further consideration for the use in mission critical networking (Fuchs et al., 2011). However, combining fingerprinting methods with RSSI using machine learning AI (artificial intelligence) has the potential to yield good results.

Given our large training sets, it is unlikely that additional sampling will increase accuracy. Adding additional hardware and altering the model are the only alternatives. For example, ray-tracing models that account for walls and other obstacles have been employed. Pursuing the modelling strategy, however, we are left with a trade-off in model complexity vs. accuracy, and such questions are not easily answered. For example, it is unclear if building models at the level of detail where one must model all items impacting signal propagation (walls, large bookshelves, etc.) would be worth the improvements in localization accuracy (Elnahrawy et al., 2004; Schaubach et al., 1992). 
Some of these localization methods are now used in commercially available solutions. With regards to the availability of technologies, two representatives from traditional manufacturers with long-term experience in the field were chosen for the purposes of our research.

\section{Cisco Meraki}

In the Meraki architecture, there is only one hardware component: the access points. All control, configuration, optimization, and mobility controls are centralized and delivered as service by the Meraki Cloud Controller (MCC) from Meraki's data centres. By eliminating separate controllers, and moving intelligence into the cloud, hosted wireless LANs reduce deployment time and complexity while enabling multi-site, scalable wireless LANs. In this configuration administrator logs into the controller system through web browser and provide access to wireless network of his account. All management is done remotely through a Web browser. The bottleneck due to centralized approach is avoided in case of Meraki Cloud Controller. Meraki's cloud-based architecture provides significant advantages over legacy hardware-based solutions. This configuration provides opportunity for cost reduction for WLAN management (Dalvi et al., 2011).

Cisco Meraki Access Points generate a presence signature from any WiFi-enabled device by detecting probe requests and 802.11 data frames from any device that is associated to the network. WiFi devices typically emit a probe request at regular intervals based on the device state. Smartphones send probe requests to discover surrounding wireless networks, so that they can make the networks available to the user. Meraki cloud aggregates raw client location data reported and provides a real-time estimate on the location of WiFi (associated and nonassociated) and Bluetooth Low Energy (BLE) devices in real-time. The Scanning API delivers this data to your real-time location application, data warehouse, or business intelligence systems (Cisco Meraki, 2018).

\section{Aruba central}

Aruba Central is a unified cloud-based network operations, assurance and security platform that simplifies the deployment, management, and optimization of wireless, wired and WAN environments. With continuous monitoring, AI-based analytics provide real-time visibility and insight into what is happening in the WiFi network. The insights utilize machine learning that leverage a growing pool of network data, and deep domain experience. The result is a consistent, reliable, and timely flow of information about the RF environment, that helps IT work smarter to deliver an optimal WiFi experience, despite increasing demands and the complexity that a growing network often brings. Presence Analytics offers a value added service for Instant AP based networks to get an insight into user presence and loyalty. The Presence Analytics dashboard allows you to view the presence of users at a specific site and the frequency of user visits at a given location or site. Using this data, you can make business decisions to improve customer engagement (HPE-Aruba, 2019).

\section{WiFi client}

The IoT device associated with a particular logistics element can be any electronics that is using WiFi or Bluetooth technology. Representatives of these technologies were chosen for the experiment: Bluetooth beacon EMBC01 (Subhan et al., 2019) (Figure 1) and the development module ESP-8266 (IEEE Electron Devices Society et al., 2019) (Figure 2).

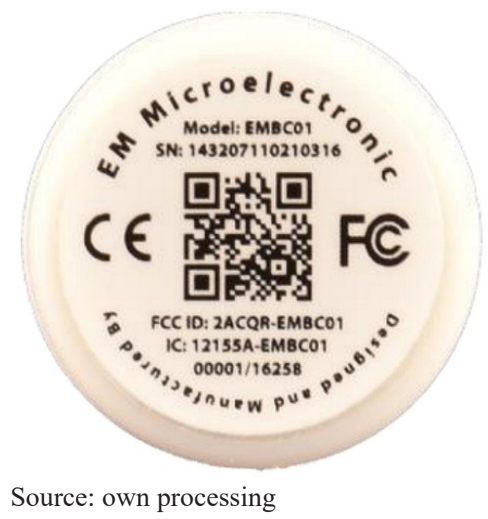

Figure 1: EMBC01.

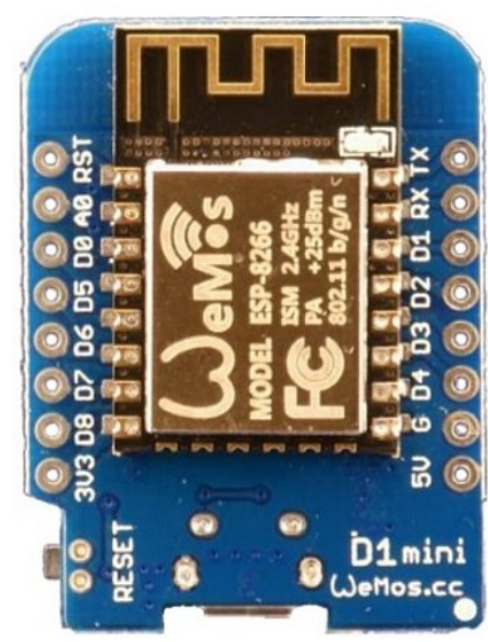

Source: own processing

Figure 2: ESP-8266. 
For the basic function of the ESP-8266 module, it was necessary to load the appropriate firmware into the processor. The following program (ESP8266 Community Forum, 2019) (Figure 3) was used:

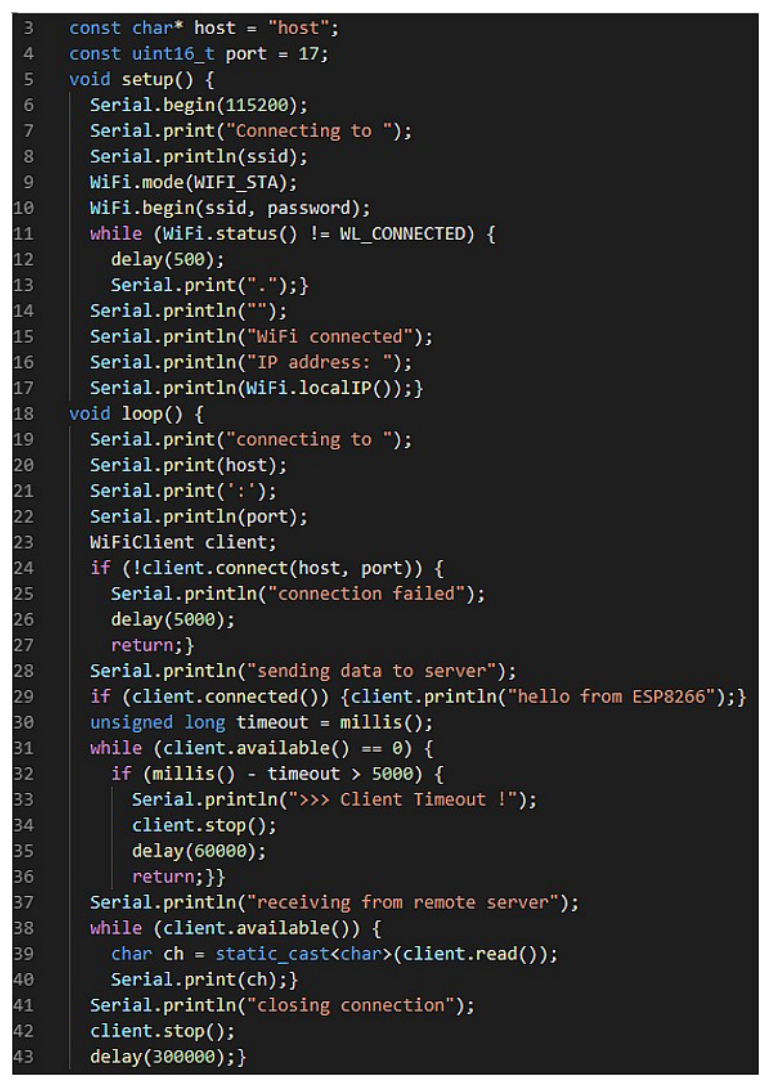

Source: own processing

\section{Experimental method}

The aim of the experiment is to verify the ability of WiFi systems to provide positional information even under restricted entry conditions. First, the layout of the AP was proposed. With respect to the floor plan in which the experiment was carried out and in combination with the limited possibility of connection to LAN infrastructure. The space selected and the limited number of APs did not allow optimal conditions to be achieved. The loadbearing parts of the building are made of reinforced concrete construction, the partitions separating individual rooms are built of burnt bricks.

The experiment focused only on associated devices. Two ESP8266 modules with WiFi were selected for the experiment. Within one measurement, the devices were always placed at a predefined location and subsequently a positional information query was sent. This measurement was repeated four times. This resulted in a sample of eight testing positions.

For the experiment, space was selected in only one part of the floor with the layout shown in Figure 4. The drawing is completed with coordinate rulers, the origin of the coordinate system is the upper left corner of the drawing of the entire floor. The APs were deployed according to Table 1.

Figure 3: ESP-8266 source code.

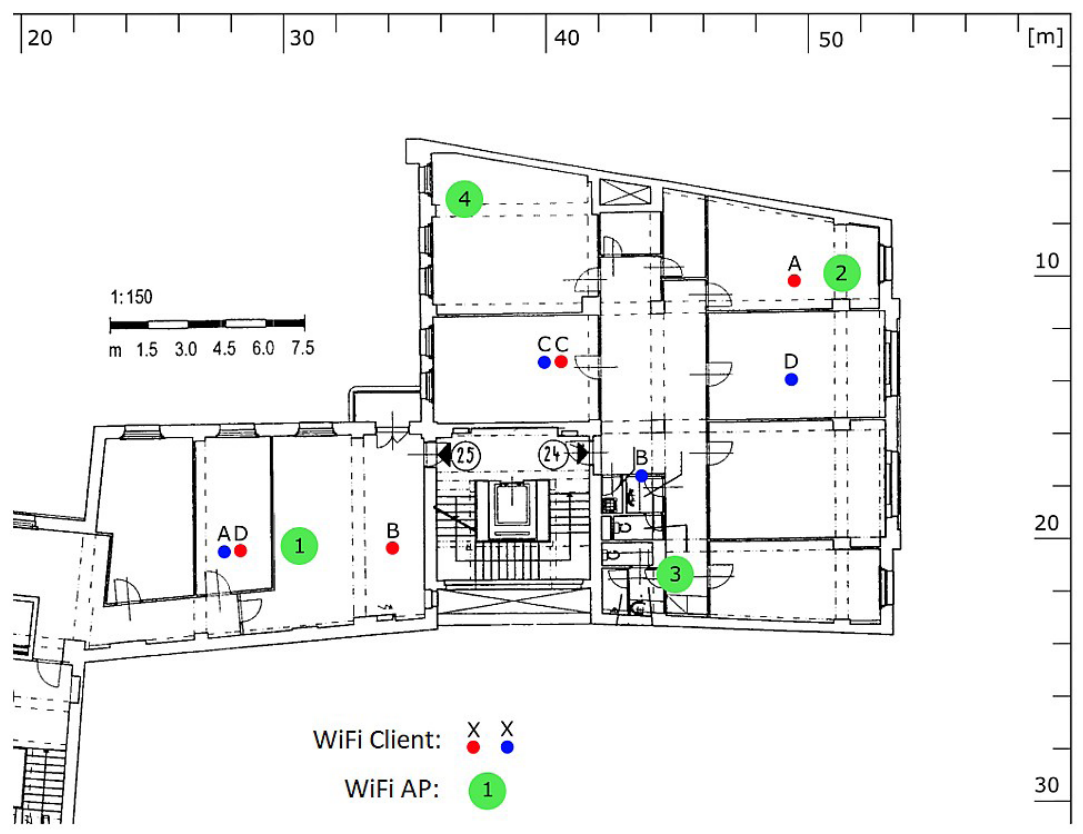

Source: own processing

Figure 4: Test building plan. 


\begin{tabular}{|l|c|c|c|c|}
\hline $\begin{array}{l}\text { AP } \\
\text { position }\end{array}$ & AP1 & AP2 & AP3 & AP4 \\
\hline $\mathrm{X}[\mathrm{m}]$ & 29.92 & 50.07 & 44.77 & 36.20 \\
\hline $\mathrm{Y}[\mathrm{m}]$ & 21.00 & 10.61 & 21.64 & 7.79 \\
\hline
\end{tabular}

Source: own processing

Table 1: AP deployment coordinates

\section{Results and discussion}

Based on the experience gained in the experiment, we provide a comparison of HPE and CISCO systems in terms of quality parameters. Four operating parameters were chosen as criteria for evaluation of WiFi solution, considering (Perez-Castillo et al., 2018):

\section{Security}

From the security point of view, the solutions are very similar. The factor most significantly affecting security is the technological solution, where the configuration of the AP is carried out through the cloud platform, so any compromise of this platform can endanger the networks themselves. Both external access solutions provide a secure API.

The security of WiFi technology itself and its physical effect in the $2.4 \mathrm{GHz}$ band was for example elaborated by (Fernández et al., 2019).

\section{Usability}

Cisco Meraki is more usable, especially due to the complexity of the offered solution that works better with individual clients' location, providing approximate location information in the form of a geographic coordinate with a sufficient number of APs. The second solution is only able to provide information about presence / absence of an object.

\section{Sustainability}

The sustainability of both solutions is very good, thanks to the cloud centralized message. In addition, Meraki's solution offers a better graphical representation of the location of each AP in the form of a map. And both the web portal and the API offer more configuration options.

\section{Interoperability}

The Meraki API is more extensive and provides more information. This makes it easier to connect this system to other systems. Important factor is also the format and complexity of the data itself. Data sources in the farm environment can be divided between the data acquired by the farm from its own internal, private data source and data obtained externally. External data can be used from public open data databases or purchased (Stočes et al., 2018).

An example of reading data from Aruba Central using the GET API is shown in Figure 5.

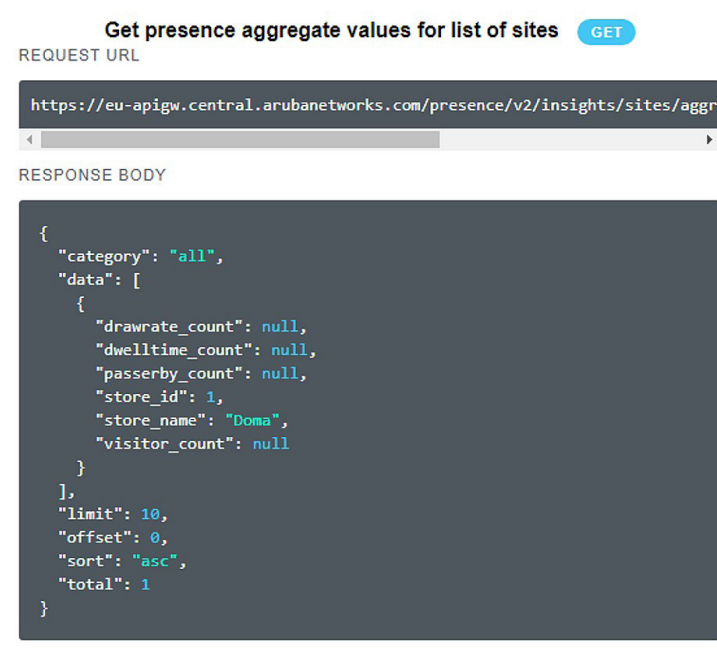

Source: own processing

Figure 5: Aruba Central API.

The result of this experiment aimed at verifying the possibility of using commercially available APs to monitor the movement of the WiFi client is shown in Table 2. It shows the different locations of the WiFi client (blue and red dots in the plan) versus to which APs were associated.

\begin{tabular}{|l|l|c|c|c|c|}
\hline Device & \multicolumn{1}{|c|}{ Position } & A & B & C & D \\
\hline Blue point & $\begin{array}{l}\text { Meraki AP } \\
\text { Presence info }\end{array}$ & AP1 & AP3 & AP4 & AP2 \\
\hline & $\begin{array}{l}\text { Aruba AP } \\
\text { Presence info }\end{array}$ & AP1 & AP2 & AP2 & AP2 \\
\hline Red point & $\begin{array}{l}\text { Meraki AP } \\
\text { Presence info }\end{array}$ & AP2 & AP1 & AP2 & AP2 \\
\hline & $\begin{array}{l}\text { Aruba AP } \\
\text { Presence info }\end{array}$ & AP2 & AP1 & AP2 & AP1 \\
\hline
\end{tabular}

Source: own processing

Table 2: AP positioning experiment results.

These results show that Meraki AP was able to better determine the location of client devices. Both solutions provided a basic orientation about the movement of objects.

\section{Conclusion}

Even though the Aruba solution performed generally worse in our comparison, it offers sufficient functionality. The intention to monitor the movement of objects, especially in agricultural enterprises, was sufficiently addressed by both 
investigated solutions. However, we recommend choosing the CISCO Meraki solution. If there is already a WiFi solution installed within the agricultural enterprise, there should be no problem monitoring the movement of WiFi clients on other systems in a similar way as described in this article.

Any commonly used devices that communicate via WiFi, such as mobile phones, computers, sensors, etc., can be used as client devices. In the experiment, the development device ESP8266 (Syed Ali et al., 2016) was used, its added value is that it is possible to create a sensory / control device on this platform. All that at low cost of tens of dollars or so. Other possible devices that can be used are those with Bluetooth technology, especially Bluetooth beacon, which is primarily intended for these purposes. Even with its small size it can operate on batteries for a long time, at a low purchase price of about 5-10 \$. For Bluetooth solutions however, it is necessary to have the appropriate infrastructure technology. Based on the research, it can be concluded that the currently available Wifi Systems can be used to monitor movement on the farm.

It is necessary securing the appropriate workforce for the task. If a subject does not employ the proper workers already, it is unfeasible to hire an entire team just for this task alone. Therefore, it is most efficient to hire the employees for a short time from a specialized agency or to outsource the whole project to a company that already has the required employees (Stočes et al., 2018).

It is commonly known that crop yield depends on crop growth variability, which is related to multiple factors that can be time-independent (e.g. substrate, topography, soil type and depth) or time-dependent. Annually linked factors may include anomalies in planting, emergence, or weather conditions. Seasonally linked factors can include plant diseases, weed development, severe climatic events, or irrigation system malfunctions (Bégué et al., 2008; Kumhálová and Matějková, 2017).

Another possible direction of research is the area of presenting the data obtained to employees of an agricultural enterprise. Alternatively, with the support of artificial intelligence, the data can be used to optimize logistics processes.

Another usage would be in BIM (building information modelling) which promises significantly advancing the architecture, engineering, and construction (AEC) market worldwide, however the low spread and adoption of BIM is still an issue. From a technology diffusion perspective, this paper proposes a game theory-based model including two firms who both are potential BIM adopters under support from the government (Yuan and Yang, 2020).

Application of this research can be, for example, monitoring of storage boxes and pallets, monitoring of machines and tools, employees, breeding animals such as cows, horses, etc.

\section{Acknowledgements}

The results and knowledge included herein have been obtained owing to support from the following institutional grant. Internal grant agency of the Faculty of Economics and Management, Czech University of Life Sciences in Prague, grant no. 20181005 - "Processing of precision agriculture and IoT data in regards to big data in agriculture ".

\section{Corresponding authors}

Ing. Vojtěch Novák

Department of Economics, Faculty of Economics and Management Czech University of Life Sciences Prague, Kamycka 129, Prague - Suchdol, 165 00, Czech Republic

Phone: +420777714484, E-mail: novakvojtech@pef.czu.cz

\section{References}

[1] Bégué, A., Todoroff, P. and Pater, J. (2008) "Multi-time scale analysis of sugarcane within-field variability: Improved crop diagnosis using satellite time series?", Precision Agriculture, Vol. 9, No. 3, pp. 161-171. E-ISSN 1573-1618, ISSN 1385-2256. DOI 10.1007/s11119-008-9063-3.

[2] Cisco Meraki (2018) "Location Analytics Introduction" [Online]. Available: https://documentation. meraki.com/MR/Monitoring_and_Reporting/Location_Analytics [Accessed: Nov. 29,. 2019].

[3] Dalvi, A., Swamy, P. and Meshram, B. B. (2011) "Centralized management approach for WLAN", In: Das V.V., Stephen J., Chaba Y. (eds) Computer Networks and Information Technologies. CNC 2011. Communications in Computer and Information Science, vol 142. Springer, Berlin, Heidelberg, pp. 578-580. ISBN 978-3-642-19541-9. DOI 10.1007/978-3-642-19542-6_113. 
[4] Elnahrawy, E., Li, X. and Martin, R. P. (2004) "The limits of localization using signal strength: A comparative study", 2004 First Annual IEEE Communications Society Conference on Sensor and Ad Hoc Communications and Networks, IEEE SECON 2004. IEEE Xplore, Santa Clara, CA, USA. ISBN 0-7803-8796-1. DOI 10.1109/SAHCN.2004.1381942.

[5] ESP8266 Community Forum (2019) "WiFiClient.ino". [Online]. Available: https://github.com/ esp8266/Arduino/blob/master/libraries/ESP8266WiFi/examples/WiFiClient/WiFiClient.ino [Accessed: April 4, 2019].

[6] Fernández, M., Guerra, D., Gil, U., Trigo, I., Peña, I. and Arrinda, A. (2019) "Measurements and analysis of temporal and spatial variability of WiFi exposure levels in the $2.4 \mathrm{GHz}$ frequency band", Measurement, Vol. 149, ISSN 0263-2241. DOI 10.1016/j.measurement.2019.106970.

[7] Fuchs, C., Aschenbruck, N., Martini, P. and Wieneke, M. (2011) "Indoor tracking for mission critical scenarios: A survey", Pervasive and Mobile Computing, Vol. 7, Vol. 1, pp. 1-15. ISSN 1574-1192. DOI 10.1016/j.pmcj.2010.07.001.

[8] HPE-Aruba (2019) "ARUBA CENTRAL" [Online]. Available: https://www.arubanetworks.com/ [Accessed: No. 29, 2019].

[9] Jermolajeva, E., Rivža, B., Aleksejeva, L., Šipilova, V., Ostrovska I. (2017) "Smart Growth as a Tool for Regional Convergence: Evidence from Latgale Region of Latvia", Economics and Sociology, Vol. 10, No. 4, 203-224. ISSN 2071-789X. DOI 10.14254/2071-789X.2017/10-4/16.

[10] Kola-Bezka M., Czupich M., Ignasiak-Szulc A. (2016), "Smart cities in Central and Eastern Europe: viable future or unfulfilled dream?", Journal of International Studies, Vol. 9, No. 1, pp. 76-87. E-ISSN 2306-3483, ISSN 2071-8330. DOI 10.14254/2071-8330.2016/9-1/6.

[11] Kumhálová, J. and Matějková, Š. (2017) "Yield variability prediction by remote sensing sensors with different spatial resolution", International Agrophysicsm, Vol. 31, pp. 195-202. E-ISSN 2300-8725, ISSN 0236-8722. DOI 10.1515/intag-2016-0046.

[12] Li, F., Liu, M., Zhang, Y. and Shen, W. (2019) "A two-level WiFi fingerprint-based indoor localization method for dangerous area monitoring", Sensors, Vol. 19, No. 19, pp. 42-43. ISSN 1424-822. DOI $10.3390 / \mathrm{s} 19194243$.

[13] Longo, E., Redondi, A. E. C. and Cesana, M. (2019) "Accurate occupancy estimation with WiFi and bluetooth/BLE packet capture", Computer Networks, 163, ISSN 1389-1286. DOI 10.1016/j.comnet.2019.106876.

[14] Parameswaran, A. T., Husain, M. I. and Upadhyaya, S. (2009) "Is RSSI a reliable parameter in sensor localization algorithms - an experimental study", IEEE International Symposium on Reliable Distributed Systems.

[15] Perez-Castillo, R., Carretero, A. G., Rodriguez, M., Caballero, I., Piattini, M., Mate, A., Kim, S. and Lee, D. (2018) "Data quality best practices in IoT environments", In: Proceedings - 2018 International Conference on the Quality of Information and Communications Technology, QUATIC 2018, Institute of Electrical and Electronics Engineers Inc., pp. 272-275.

[16] Sanchez, D., Afonso, S., Macias, E. M. and Suarez, A. (2006) "Devices location in 802.11 infrastructure networks using triangulation", Lecture Notes in Engineering and Computer Science. pp. 938-942. E-ISSN ISSN: 2078-0966

[17] Schaubach, K. R., Davis, N. J., Rappaport, T. S. (1992) "A ray tracing method for predicting path loss and delay spread in microcellular environments", IEEE Vehicular Technology Conference 1992May, pp. 932-935. DOI 10.1109/VETEC.1992.245274.

[18] Song, J. X., Liu, Y. F. (2011) "Design of underground mine locomotive monitoring and tracking management system", Procedia, Environmental Sciences, Vol. 10, pp. 484-490. ISSN 1878-0296.

[19] Stočes, M., Masner, J., Kánská, E. and Jarolímek, J. (2018) "Big Data in Internet of Things and Precision Agriculture", PROCEEDINGS - of the 27th International Scientific Conference Agrarian Perspectives XXVII. Food Safety - Food Security, Czech University Of Life Sciences Prague, Prague, pp. 353-358. ISBN 978-80-213-2890-7. E-ISSN 2464-4781, ISSN 1213-7960. 
[20] Stočes, M., Šilerová, E., Vaněk, J., Jarolímek, J.and Šimek, P. (2018) "Možnosti využití otevřených dat v sektoru cukr - Cukrová řepa" (in Czech), Listy cukrovarnické a řeparské, Vol. 134, pp. 117-121. E-ISSN 1805-9708, ISSN 1210-3306.

[21] Stočes, M., Vaněk, J., Masner, J. and Pavlík, J. (2016) "Internet of things (IoT) in agriculture - Selected aspects", Agris On-line Papers in Economics and Informatics, Vol. 8, No. 1, pp. 83-88. ISSN 1804-1930. DOI 10.7160/aol.2016.080108.

[22] Subhan, F., Khan, A., Saleem, S., Ahmed, S., Imran, M., Asghar, Z. and Bangash, J. I. (2019) "Experimental analysis of received signals strength in Bluetooth Low Energy (BLE) and its effect on distance and position estimation. Transactions on Emerging Telecommunications Technologies". Transaction on Energing Telecommunications Technologies. E- ISSN 2161-3915. DOI 10.1002/ett.3793.

[23] Syed Ali, A., Zanzinger, Z., Debose, D. and Stephens, B. (2016) "Open Source Building Science Sensors (OSBSS): A low-cost Arduino-based platform for long-term indoor environmental data collection", Building and Environment, Vol. 100, pp. 114-126, ISSN 0360-1323. DOI 10.1016/j.buildenv.2016.02.010.

[24] Thakare, S. and Bhagat, P. H. (2019) "Arduino-Based Smart Irrigation Using Sensors and ESP8266 WiFi Module", Proceedings of the $2^{\text {nd }}$ International Conference on Intelligent Computing and Control Systems, ICICCS 2018. DOI 10.1109/ICCONS.2018.8663041.

[25] Vasisht, D., Kumar, S. and Katabi, D. (2016) "Decimeter-Level Localization with a Single WiFi Access Point", Nsdi 2016, $13^{\text {th }}$ USENIX Symposium on Networked Systems Design and Implementation, Santa Clara, CA, USA.

[26] Yuan, H. and Yang, Y. (2020) "BIM Adoption under Government Subsidy: Technology Diffusion Perspective", Journal of Construction Engineering and Management, Vol. 146, No. 1. E-ISSN 1943-7862, ISSN 0733-9364. DOI 10.1061/(ASCE)CO.1943-7862.0001733.

[27] Żelazny, R. (2017) "Determinants and measurement of smart growth: evidence from Poland", Journal of International Studies, Vol. 10, No. 1, pp. 34-45. E-ISSN 2306-3483, ISSN 2071-8330. DOI 10.14254/2071-8330.2017/10-1/2 